\title{
Article
}

\section{Triggering language and maths anxiety in non-medical prescribing students}

Smith, Charlotte and Penazzi, Davide

Available at http://clok.uclan.ac.uk/33349/

Smith, Charlotte and Penazzi, Davide ORCID: 0000-0002-9732-1577 (2020) Triggering language and maths anxiety in non-medical prescribing students. Journal of Prescribing Practice, 2 (5). ISSN 2631-8385

It is advisable to refer to the publisher's version if you intend to cite from the work. 10.12968/jprp.2020.2.5.226

For more information about UCLan's research in this area go to http://www.uclan.ac.uk/researchgroups/ and search for < name of research Group>.

For information about Research generally at UCLan please go to http://www.uclan.ac.uk/research/

All outputs in CLoK are protected by Intellectual Property Rights law, including Copyright law. Copyright, IPR and Moral Rights for the works on this site are retained by the individual authors and/or other copyright owners. Terms and conditions for use of this material are defined in the policies page.

\section{CLoK}

Central Lancashire online Knowledge www.clok.uclan.ac.uk

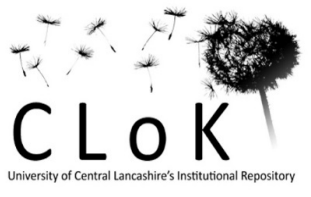




\title{
Triggering language and Maths Anxiety in Non-Medical Prescribing students.
}

\begin{abstract}
Maths anxiety is a debilitating fear of mathematics which often stems from early learning experiences. Despite their ability to confidently perform complex numerical tasks such as drug calculations as an intrinsic part of their role, health professionals often disclose experiencing maths anxiety. Health professionals who have returned to education to study Non-Medical Prescribing (NMP) are required to undertake a numeracy exam, which can trigger symptoms of maths anxiety. This quantitative study aimed to identify whether the use of professional terminology in place of mathematical vocabulary impacts on the teaching and learning of numeracy with NMP students, and identifies that use of terminology more closely aligned with health professionals' language results in lower levels of anxiety than using school-like mathematical terminology. The findings of this study can be used to inform supportive teaching practices for health professional educational courses which have a numeracy component.
\end{abstract}

\section{Keywords}

Mathematics anxiety, Non-Medical Prescribing, Adult Learners, Numeracy Testing

\section{Key Points}

Health professionals returning to education often disclose experiencing Maths anxiety. This can have particular impact when a numeracy exam is included in the assessment strategy, as is the case for NMP students. 
Early learning experiences of Mathematics can have long-term impact. Memories of such experiences can trigger anxiety and impact on student outcomes in numeracy. Teachers need to be aware of this, and develop strategies to manage and minimise maths anxiety.

In this study the researchers show how the use of professional terminology, more familiar to the practice of the NMP students, produces lower levels of mathematical anxiety than using mathematical vocabulary such as "mathematics" or "numeracy".

\section{Reflective Questions}

As a prescribing practitioner, what sort of numerical activities do you undertake?

What numeracy support/resources are available for you as prescribers in your practice areas? How might this be improved?

How might you support a student of NMP to better understand a numerical activity that they are finding challenging?

\section{Introduction:}

Adult learners of numeracy commonly experience maths anxiety for a number of reasons which may be related to early experience of learning maths (Clements and Sarama. 2014; 
Kirkland. 2016; Marshall et al. 2017), a fixed mindset surrounding the ability to learn and improve at maths (Sun. 2014; Ruef. 2018) and the ability and experience of teaching staff (Stoehr. 2017). Maths anxiety can be linked directly with numerical and cognitive errors (Bull. 2009; Wright. 2009; McMullan et al. 2009; Dyjur et al. 2011), and can have long-term impact on life choices and decision-making (Morsanyi et al. 2014).

For students of Non-Medical Prescribing (NMP) there are potential further consequences for the impact of maths anxiety. To define NMP, a range of suitably qualified non-medical health professionals are able to prescribe products for patients, either independently or in partnership with a medical professional. Students undertaking NMP courses are registered health professionals experienced in their professional practice, and are assessed in clinical skills, critical thinking, pharmacology and numeracy. Typically, NMP students undertake one (or perhaps more, depending on the hosting Higher Education Institution (HEI)) numeracy session as part of their NMP training.

Numeracy skills are key to prescribing practice for a range of related clinical activities. Drug calculation, dose and frequency might be the obvious computations associated with prescribing, but there are also lesser-acknowledged numerical skills such as wound measurement, calculating half-lives, deprescribing, use of syringe-drivers and taking measurements for medical devices amongst others. The potential for adverse outcomes related to numeracy errors is therefore significant. In 2018, the governing body for nurses and midwives, the NMC, rewrote its Standards for Prescribing Programmes (NMC. 2018) but retained the criteria of, 
"successfully passing a numeracy assessment related to prescribing and calculation of medicines (the numeracy assessment must be passed with a score of $100 \%$ )". (NMC. 2018: p12)

The decision to retain this pre-requisite reinforces the level of importance placed on numeracy for safe and effective prescribing practice - in other words, there is no escape from numeracy for NMP students, nor should there be if the patient's health and safety is to remain the focus of all prescribing activity (Royal Pharmacological Society. 2016). Rather, when working with adult learners and returning students, teachers need to be aware of the possible previous negative experience of learning mathematics that students bring to the table. Consequently, teachers need to develop mechanisms to empower students who already have some form of mathematics anxiety to engage with the mathematical component of the course. Here, the authors propose that a necessary aspect of this is to use language which helps students to make connections between the numeracy assessment and their professional practice, and to avoid language which might trigger memories of past negative learning experiences. The research question addressed was thus, "Is maths anxiety reduced when "mathematical vocabulary" is replaced with "professional terminology"?

\section{Maths anxiety in nursing/health professionals}

The notion of mathematical anxiety (MA) was introduced in the 1950s, then referred to as "Mathphobia". Among the various definitions of MA, widely accepted is that of Spicer 
(2004), focusing on its debilitating aspect: "anxiety that is present or produced surrounding mathematical content eliciting an emotion that blocks a person's reasoning ability when confronted with a mathematical situation".

Maths Anxiety can develop as early as during primary school (Krinzinger et al. 2009; Vukovich et al. 2013), but is understood to be prevalent during secondary school years (Dwoker et al. 2016). The origins of maths anxiety are not fully understood, but it is believed they stem from a traumatic event, as in the example described by Johnston-Wilder et al. (2013), where being shamed in front of the class for giving a wrong answer caused a protracted state of fear for the subject; or from a process of disengagement, where the students develop a pattern of avoidance (Turner et al. 2002) due to repeated failure and the emotional response that ensues from failure. (Johnston-Wilder at al. 2015). It could be argued that teachers themselves are a key factor in the development of maths anxiety mathematics teaching in British schools is described by Nardi and Steward (2003) using the acronym TIRED: Tedious, Isolating, Rota learning, Elitist and Depersonalizing. Whilst this method suits some students (though mainly the successful mathematics graduate), it could not be further from the emotional sphere of NMP students who, as people working in caring professions, thrive on human interaction, relational working, critical thinking and personcentred approaches.

It is thus not surprising, and a well-documented phenomenon, that most students and practitioners in the caring profession have some level of Maths Anxiety. (Perry. 2004) 
The results of a piece of qualitative research undertaken as part of a Masters in Education by one of the authors identified choice of university, occupation, shopping decisions and tax payment as having been directly impacted on by maths anxiety. One participant disclosed that maths anxiety had effectively altered the trajectory of their university career:

“There's been plenty of opportunity for me to do my prescribing but I've always put it off because of the maths test. I should have gone to a different university... but there was a maths test to start the course, so I just came [here] instead." (Participant, qualitative research study (unpublished))

Maths Anxiety can manifest itself in various ways, and at differing levels. From "a state of discomfort that occurs in response to situations involving mathematical tasks that are perceived as threatening to self-esteem" (Trujilo and Hadfield. 1999) to, in the most extreme cases, panic and physiological symptoms such as sweaty palms, nausea, and heart palpitations (Perry. 2004) which are triggered at the mere sight of mathematical symbolism. Maths Anxiety can be debilitating and interfere with decision-making processes (Ashcraft and Moore. 2009). As demonstrated in the above quote, it is not unusual for students with Maths Anxiety to try to avoid courses with a mathematics content (Meece et al. 1990)

Maths Anxiety is a complicated construct and as such is difficult to measure as a "standalone" concept. As a result, the authors' focus for this study is on three more readily measurable factors of mathematics anxiety:

1. Maths Test Anxiety (TA) (anxiety experienced specifically related to maths tests or examinations) 
2. Numerical Task Anxiety (NA) (anxiety experienced when performing non-assessed tasks such as listening to a lecture or working on a maths question)

3. Maths Course Anxiety (MCA) (anxiety related to the whole experience of studying maths, which encompasses the previous two (Alexander and Martray. 1989))

\subsection{The origin of the question}

This piece of quantitative research pursues the theme of language used in teaching and learning numeracy, a theme which emerged in the author's Master's research where participants identified a difference between what they perceived to be "regular maths" (which can be defined as maths as a discipline) and "nursing maths" (which can be defined as the numeracy skills nurses regularly encountered in practice). Interestingly, participants viewed these two as separate and distinct skills, disclosing low levels of anxiety for "nursing maths", which they saw as part of their role and felt confident in undertaking, and higher levels of anxiety for "regular maths", which they perceived as something unrelated to their roles and beyond their capacity to master. This is illustrated in the following quote from a participant of the pilot study,

“[drug calculations] just seem to make sense to me 'cause I'm a nurse and 'cause you're doing it day in, day out... I must just be able to do that type of maths. So, I think my issue is maths as a whole. Rather than nursing maths". (Participant, qualitative research study (unpublished))

Another example of language aligned to role is present in this participant's quote: 
"I enjoy problem-solving. But if you just gave me a "what is a third of that" type thing, no, I wouldn't like that." (Participant, qualitative research study (unpublished))

Here, the participant sees "problem solving" as a skill aligned with their professional practice, and feels comfortable - even enjoys - this numeracy activity. When traditional mathematical language is used however, they express discomfort.

It is possible that this identification of a different "type" of maths with a distinct title is a coping strategy. Perhaps the language of maths triggers memories of early negative learning experiences - this is considered to be the case in other types of anxiety and trauma (Ehring and Ehlers, 2011). Detaching from this and situating themselves in their comfort zone might serve to protect students throughout the learning experience.

The study discussed in this paper is the direct result of this emergent theme of language. It is a quantitative analysis of the impact of the language used in numeracy teaching and learning interventions for NMP students. Four research questions were proposed. These are as follows:

Question 1: Does the use of the word Mathematics rather than drug calculation affect the Maths Course Anxiety of the students?

Question 2: Is there a significative difference between TA and NA? And, if so, which one is more prominent?

Question 3: Do the words Mathematics and Drug Calculation make a difference with respect to TA? 
Question 4: Do the words Mathematics and Drug Calculation make a difference with respect to NA?

\section{Methodology}

The Abbreviated Maths Anxiety Scale (AMAS), developed by Hopko et al. (2003) was selected to evaluate the impact of language use in numeracy teaching for NMP students. This tool was selected for ease of use - it constitutes a shorter questionnaire than the original Math Anxiety Rating Scale (MARS) (Richardson and Suinn. 1972), which contains 98 questions, and the revised version (MARS-R) (Plake and Parker. 1982).

The original AMAS consists of 9 Likert scale questions. Participants are asked to answer with a value from 1 (Fine) to 5 (Highly Anxious) to how they felt in situations related to aspects of their learning of mathematics. The main advantage of using the AMAS, apart from its brevity, is that the 9 questions can be divided in the two factors: Numerical Task Anxiety (NA) and Maths Test Anxiety (TA). All nine questions contribute to the Maths Course Anxiety (MCA). This was already identified in the original article by Hopko at al. (2003). For the purpose of this study, the terminology of Alexander and Martray (1989) was adopted in the first instance. 


\begin{tabular}{|l|l|}
\hline $\begin{array}{l}\text { 1. Having to use the tables in the back of a } \\
\text { math book. }\end{array}$ & 2. Thinking about an upcoming math test 1 \\
day before. \\
\hline equation on the blackboard. & 4. Taking an examination in a math course. \\
\hline 6. Listening to a lecture in math class. & 5. Being given a homework assignment of \\
7. Listening to another student explain a & many difficult problems that is due the next \\
math formula. & class meeting \\
\hline 9. Starting a new chapter in a math book. & \\
\hline
\end{tabular}

Table 1: The questions in the AMAS divided into the factors NA and TA.

The summary of all of the responses provides a rating to the participant's overall level of maths anxiety, from 9 (least anxious) to 45 (most anxious). Each participant's NA can be evaluated, obtaining a score from 5 to 25; as can their TA, obtaining a score from 4 to 20 .

Two linguistic modifications were made to the original questionnaire. First, "American" terms were changed to align with the language used in British universities (for example, "pop quiz" was replaced with "surprise test"). Second, to increase the relevance of the statements to NMP students, "math book" was replaced with "BNF" - the British National Formulary, the core pharmaceutical reference book that NMP students use. 
Most importantly, two different versions of the questionnaire were created for this study.

In one, the word "mathematics" was retained, (this is referred to as the Maths

Questionnaire), and in the second it was replaced with the term "drug calculations" (this is referred to as the "Drug Questionnaire"). The questions are presented in Table 2, in Appendix 1 are the full questionnaires.

\begin{tabular}{|c|c|}
\hline Maths Questionnaire & Drug Questionnaire \\
\hline $\begin{array}{l}\text { 1. Having to use the mathematics tables in } \\
\text { the BNF }\end{array}$ & $\begin{array}{l}\text { 1. Having to use the drug calculations } \\
\text { tables in the BNF }\end{array}$ \\
\hline $\begin{array}{l}\text { 2. Thinking about a mathematics test the } \\
\text { day before the test occurs }\end{array}$ & $\begin{array}{l}\text { 2. Thinking about a drug calculations test } \\
\text { the day before the test occurs }\end{array}$ \\
\hline $\begin{array}{l}\text { 3. Watching the tutor doing mathematics } \\
\text { on the whiteboard }\end{array}$ & $\begin{array}{l}\text { 3. Watching the tutor doing drug } \\
\text { calculations on the whiteboard }\end{array}$ \\
\hline 4. Taking a mathematics exam & 4. Taking a drug calculations exam \\
\hline $\begin{array}{l}\text { 5. Being given an assignment on } \\
\text { mathematics, to be submitted in the } \\
\text { next lecture }\end{array}$ & $\begin{array}{l}\text { 5. Being given an assignment on drug } \\
\text { calculations, to be submitted in the next } \\
\text { lecture }\end{array}$ \\
\hline 6. Listening to a lecture on mathematics & $\begin{array}{l}\text { 6. Listening to a lecture on drug } \\
\text { calculations }\end{array}$ \\
\hline $\begin{array}{l}\text { 7. Listening to another student explain a } \\
\text { mathematics formula }\end{array}$ & $\begin{array}{l}\text { 7. Listening to another student explain a } \\
\text { drug calculation formula }\end{array}$ \\
\hline $\begin{array}{l}\text { 8. Being given a surprise test on } \\
\text { mathematics in a lecture }\end{array}$ & $\begin{array}{l}\text { 8. Being given a surprise test on drug } \\
\text { calculations in a lecture }\end{array}$ \\
\hline
\end{tabular}


Table 2: The questions in the Maths and Drug questionnaires

Institutional ethical approval and informed consent was obtained. A copy of the questionnaire was given to each participant in one of the early lectures of their NMP course. Students were asked to complete the anonymous questionnaires individually. The lecturer disseminating the questionnaire was instructed to avoid using the terms "mathematics" or "drug calculations" when explaining the purpose of the activity so as not to influence responses.

88 questionnaires were completed across 4 cohorts of students. Of these 47 were Maths Questionnaires and 41 Drug Questionnaires. The results were analysed in relation to the research questions. The results of these will now be discussed.

\subsection{Results}

Out of the 88 participants, 61 expressed a level of anxiety of 4 or 5 to at least one question, showing that the experience of doing the numeracy component of their course causes anxiety to the majority of students. 
Question 1: Does the use of the word Mathematics rather than drug calculation affect the Maths Course Anxiety (MCA) of the students?

A t-test (one-tailed, unequal variances, as determined by the f-test) was performed with the following hypotheses:

HO: The mean value of the MCA in completing the Mathematics Questionnaire is less or equal to that in the Drug Questionnaire.

$\mathrm{H} 1$ : The mean values of the MCA in the Mathematics Questionnaire is greater than that in the Drug Questionnaire.

Outcome:

The obtained mean for the Mathematics Questionnaire is 25.72 , whilst for the Drug Questionnaire is 22.68 .

The t-test shows a significant decrease of the MCA (at a significance level of $0.05, p=0.4777$ ) by using the words Drug Calculations in place of Mathematics.

The resulting data can be used to further explore the main cause of this anxiety, in particular: how much does the choice of words contribute towards TA and NA?

The following question focuses on identifying whether it is the test or the subject itself causing the anxiety: 
Question 2: is there a significative difference between Mathematical Task Anxiety (TA) and Numerical Anxiety (NA)? And, if so, which one is more prominent?

A t-test (paired, two tailed) between the weighted average test anxiety (WTA) and weighted average mathematics anxiety (wNA) obtained by each student in the questionnaire was used. ${ }^{1}$

The hypotheses are:

HO: $\quad$ WTA-wNA=0;

H1: $\quad$ WTA-wNA $\neq 0$.

The t-tests were performed for all Mathematics questionnaires, all Drug questionnaires and to all questionnaires, obtaining the following results (Table 3):

\begin{tabular}{|l|l|l|l|}
\hline & $\begin{array}{l}\text { Mathematics } \\
\text { Questionnaires }\end{array}$ & Drug & Questionnaires \\
\hline WTA-wNA & 1.0787 & 1.3354 & Questionnaires \\
\hline P-value & $1.56 \times 10^{-11}$ & $3.6 \times 10^{-11}$ & 1.1983 \\
\hline
\end{tabular}

Table 3: Results from paired t-test

\footnotetext{
${ }^{1}$ As there are 5 questions measuring NA and only 4 questions measuring TA, to be able to compare them we use a weighted NA average (WNA) and a weighted TA average (WTA): WNA $=\frac{\text { NA average }}{5} ; \mathrm{wTA}=\frac{\text { MTA average }}{4}$.
} 
In each case there is a significative difference (at significance level 0.01) indicating that TA is more prevalent than NA, regardless of the word used in the questionnaire.

However, an interesting observation is that the difference of the weighted average is larger for the questionnaires using the words "Drug Calculations". Thus, separate investigation of NA and TA is required to identify the effect the use of the words for each factor.

Question 3: Do the words "Mathematics" and "Drug Calculation" make a difference with respect to TA?

A t-test (one-tailed, equal variances, as determined by the f-test) was performed, comparing the averages in the TA results for the Mathematics Questionnaires (TAM) and the Drug Questionnaires (TAD).

HO: TAM $<=$ TAD

$\mathrm{H} 1: \mathrm{TAM}>\mathrm{TAD}$

The values $T A M=13.830$ and $T A D=13.049$ are obtained, but this difference is not significative $(p=0.21696)$, for which we cannot reject the null hypothesis. Hence the use of the word "Mathematics" does not increase significantly Mathematics Test Anxiety. 
Question 4: Do the words Mathematics and Drug Calculation make a difference with respect to NA?

A t-test (one-tailed, unequal variances, as determined by the f-test) was used, comparing the averages in the mathematics anxiety proper results for the Mathematics Questionnaires (NAM) and the Drug Questionnaires (NAD).

HO: NAM $<=N A D$

$H 1: N A M>N A D$

The values $N A M=11.894$ and $N A D=9.6341$ were obtained, with the t-test showing significance at a 0.05 level ( $p=0.012949)$. Thus, the null hypothesis can be rejected, and it is observed that the use of the word "Drug Calculation" instead of "Mathematics" lowers the level of Numerical Task Anxiety.

\section{Discussion}

The fact that a larger proportion of students identify levels of anxiety than those who do not in relation to numeracy is in itself significant and presents potential issues for teaching and learning. The study shows that using "professional terminology" rather than "mathematical vocabulary" has a positive impact by reducing anxiety associated with the numeracy component of the course. Furthermore, this improvement happens in the whole course experience (MCA) and when students perform non-assessed numerical tasks (i.e. in 
classroom and in personal study). It does not, however, appear to affect anxiety associated with the numeracy test - this further supports the idea that TA is a separate construct from NA.

An assumption, supported by the pilot study, is that when language is contextualised to reflect practice, students commence their learning process from the comfort zone and the threat of having to learn an "alien" subject is reduced. However, as Senninger's (2000) Learning Zone Model, and Johnston-Wilder and Lee's (2013) Growth Zone Model (see fig 4) show, where people may feel safe and unchallenged in the comfort zone, this is not where learning occurs. Conversely, learning cannot occur in the "Panic Zone" either, as this space is dominated by anxiety which prevents effective learning. Senninger (2000) asserts that the space between comfort and panic is where learning happens. Thus, teachers need to exercise caution in the creation of an effective learning environment.

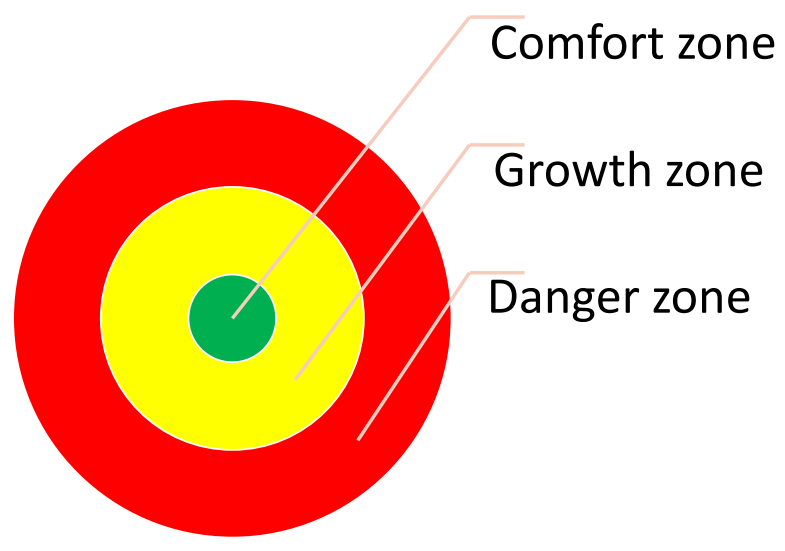

Fig 4: The Learning Zone Model

In an environment which embraces a "fixed mindset" (Dweck. 2008) this model takes a different shape (see Fig. 5). The fixed mindset is not uncommon in mathematics teaching 
and learning. For example, there are commonly held conceptions that one is either "a maths person", that is to say "naturally" numerate, or not - and that this is an unalterable state (Sun, 2014; Ruef, 2018). This induces the individuals to believe that there is no further mathematics that they can learn, thus any mention of "novel" mathematics immediately places them in the Danger zone. This is the case of students with moderate Mathematics Anxiety.

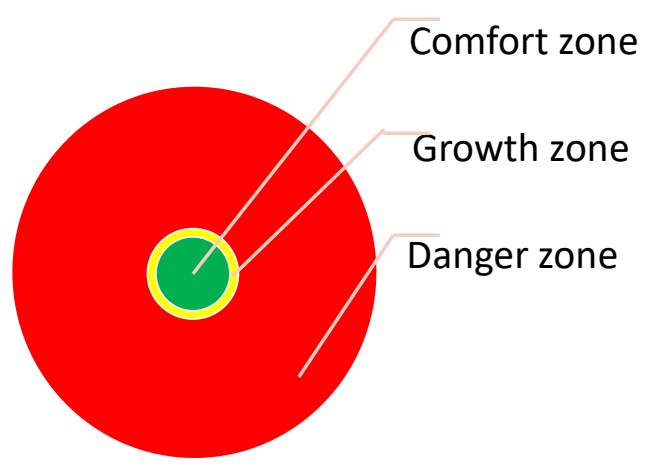

Fig. 5: The Learning Zone model in a Fixed Mindset

In more extreme cases of Mathematics Anxiety, the mention of any form of mathematics immediately places the students in the Danger Zone, depicted in Fig. 6.

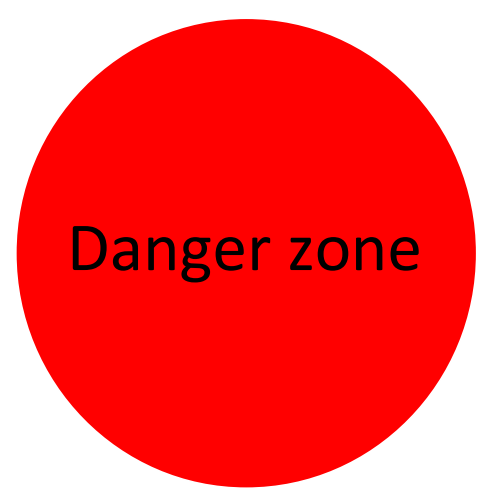

Fig 6: The Learning Zone Model for mathematically anxious students 
Therefore, using language aligned to students' professional practice and avoiding "mathematical terminology" might situate them in the comfort zone, from which they can be led by a more knowing other (Vygotsky. 1978) to the more challenging and risky space of the learning zone. During this process it is important both to develop mathematical resilience in the student (Johnston-Wilder and Lee, 2013), and to avoid "triggering" words and processes that could lead students to a fixed mindset (Fig. 5) or a Mathematically Anxious mindset (Fig. 6).

With regard to NA, the data suggests that students attach lower levels of anxiety to teaching and learning activities when language aligned to their professional practice is used in classroom numeracy activities. Teachers are thus presented with the opportunity to assist in the creation of a learning zone and the development of a growth mindset mentality by adapting their language accordingly. Of course, it is unlikely that language alone can eradicate anxiety surrounding NA - an effective learning zone also depends on an established learning community, knowledgeable teachers and engaging content for example - but it can be understood that language does have an impact on the anxiety students experience with regard to NA.

In terms of TA, language has little impact on reducing anxiety related to the examination of mathematics - students expressed feeling anxious at the prospect of being tested in maths no matter what terminology was used. Perhaps this is because tests and exams are intrinsically anxiety-provoking, so language does little to reduce this. It is possible that in the case of TA in NMP courses, the $100 \%$ pass mark is the focus of anxiety - this is a 
potential area for future research. Nonetheless, using a practice-focused language in the classroom allows students to better engage with the subject, and even with high anxiety levels when performing the final exam, be more prepared for it.

\section{Conclusion}

Language has significant consequences for teaching and learning - numeracy is an essential skill for NMP practitioners, and teachers have a duty to design and deliver interventions which best promote effective learning of the subject. With high-stakes activities such as drug calculation, it is imperative that NMP students finish their course of study feeling confident to undertake the numerical activities necessary for safe and effective calculation. Based on the outcomes of this study, a reasonable assumption might be that along with other anxiety-reducing measures such as the creation of an inclusive learning community, one strategy teachers could immediately adopt is to align the language they use when teaching numeracy more closely with the language NMP students use in practice.

Based on this research study, the authors identified the following recommendations for teachers of numeracy:

- Ease the students into the numeracy classes using language related to their specific practice rather than terminology which might reflect traditional "school" learning (for example, "drug calculations" rather than "maths problems")

- Engage students in discussion about the relevance of classroom material to practice - for example, when presenting a topic or problem, ask students if they have experienced a similar topic or problem in practice, and encourage students to share this with the group. 
- As the main source of anxiety appears to be the numeracy test itself, incorporate in the classes techniques for test anxiety management. This might include typical exam preparation and management techniques such as taking breaks, time management, how to check answers and reading questions carefully.

\section{References:}

Alexander L, Martray C. 1989). he Development of an Abbreviated Version of the Mathematics Anxiety Rating Scale. Measurement and Evaluation in Counseling and Development, 22(3): 143-150.

Ashcraft M H, Moore A M. 2009. Mathematics anxiety and the affective drop in performance. Journal of Psychoeducational assessment, 27(3): 197-205.

Bull H. 2009. Identifying maths anxiety in student nurses and focusing remedial work. Journal of Further and Higher Education 33(1): 71-81. Available at: https://www.tandfonline.com/doi/abs/10.1080/03098770802638689 (Accessed: January 2020)

Clements D, Sarama J. 2014. Learning and Teaching Early Math: The Learning Trajectories Approach ( $2^{\text {nd }}$ ed.) UK: Routledge. 
Dweck C. 2008. Mindsets and math/science achievement. Prepared for the Carnegie Corporation of New York-Institute for Advanced Study Commission on Mathematics and Science Education. Available at: http://www.growthmindsetmaths.com/uploads/2/3/7/7/ 23776169/mindset and math science achievement - nov 2013.pdf (Accessed: January 2020)

Dyjur L, Rankin J, Lane A. 2011. Maths for medications: an analytical exemplar of the social organization of nurses' knowledge. Nursing Philosophy 12(3): 200-13. Available at: doi: https://www.ncbi.nlm.nih.gov/pubmed/21668619 (Accessed: January 2020)

Dowker A, Sarkar A, Looi CY. 2016. Mathematics Anxiety: What Have We Learned in 60 Years? Frontiers in Psychology (7): 508.

Ehring, T. and Ehlers, A. (2011) Enhanced Priming for Trauma-Related Words Predicts Posttraumatic Stress Disorder Journal of Abnormal Psychology 120(1): 234-239 Available at: https://psycnet.apa.org/fulltext/2010-23150-001.pdf (Accessed: February 2020)

Hopko D R, Mahadevan R, Bare R L, Hunt M K. 2003. The Abbreviated Math Anxiety Scale (AMAS): Construction, Validity, and Reliability. Assessment, 10(2): 178-182.

Johnston-Wilder S, Lee C, Garton L, Goodlad S, Brindley J. 2013. Developing coaches for mathematical resilience. In: ICERI 2013, 6th International Conference on Education, Research and Innovation, 18-20 Nov 2013, Seville, Spain. 
Johnston-Wilder S, Lee C, Brindley J, Garton E. 2015. Developing mathematical resilience in school students who have experiences repeated failure. In: ICERI 2015, 8th International Conference of Education, Research and Innovation, Seville, Spain.

Joint Formulary Committee (2019) BNF 78: September 2019-March 2020. London: Pharmaceutical Press.

Kirkland H. 2016, "Maths anxiety" - Isn't it just a dislike for learning mathematics?. ATM Journals Mathematics Teaching 250: 11-13. Available at: https://www.atm.org.uk/write/ MediaUploads/Journals/MT250/MT250-16-04.pdf (Accessed: January 2020).

Krinzinger H, Kaufmann L, Willmes K. 2009. Math Anxiety and Math Ability in Early Primary School Years. Journal of Psychoeducational Assessment, 27(3): 206-225.

Marshall E, Staddon R, Wilson D, Mann V. 2017. Addressing maths anxiety and engaging students with maths within the curriculum. MSOR Connections. 15 (3). Available at: https://journals.gre.ac.uk/index.php/msor/article/view/555/pdf (Accessed: January 2020).

Meece J L, Wigfield A, Eccles J S. 1990. Predictors of math anxiety and its influence on young adolescents' course enrollment intentions and performance in mathematics. Journal of Educational Psychology. 82(1): 60-70. 
McMullan M, Jones R, Lea S. 2012. Math anxiety, self-efficacy, and ability in British undergraduate nursing students. Research in Nursing and Health 35(2):178-86. Available at: doi: https://www.ncbi.nlm.nih.gov/pubmed/22261975 (Accessed: January 2020).

Morsanyi K, Busdraghi C, Primi C. 2014. Mathematical anxiety is linked to reduced cognitive reflection: a potential road from discomfort in the mathematics classroom to susceptibility to biases. Behav Brain Funct (10) 31.

Nardi E, Steward S. 2003. Is Mathematics T.I.R.E.D? A Profile of Quiet Disaffection in the Secondary Mathematics Classroom. British Educational Research Journal. 29: 345-366.

Nursing and Midwifery Council. (2018). Standards for Prescribing Programmes London. Nursing and Midwifery Council. Available at: https://www.nmc.org.uk/globalassets/ sitedocuments/education-standards/programme-standards-prescribing.pdf (Accessed: February 2020)

Perry A B. 2004. Decreasing math anxiety in college students. College student journal. 38(2): 321-325.

Plake B S, Parker C S. 1982. The development and validation of a revised version of the Mathematics Anxiety Rating Scale. Educational and Psychological Measurement. 42: 551557. 
Richardson F C, Suinn R M. 1972. The Mathematics Anxiety Rating Scale. Journal of Counselling Psychology. 19: 551-554.

Royal Pharmaceutical Society. 2016. A competency framework for all prescribers. London, RPS .Available at: https://www.rpharms.com/resources/frameworks/prescriberscompetency-framework (Accessed: February 2020).

Ruef J, Sweeney S, Willingham G. 2018. What does it mean to be good at math?. Tools for discovery. Available at: https://cpb-us-e1.wpmucdn.com/blogs.uoregon.edu/ dist/2/16744/files/2018/10/What-does-it-mean-to-be-good-at-math-28zia2u.png (Accessed: February 2020)

Senninger T. 2000. The Learning Zone Model - ThemPra Social Pedagogy. [online] ThemPra Social Pedagogy. Available at: http://www.thempra.org.uk/social-pedagogy/key-conceptsin-social-pedagogy/the-learning-zone-model/

Spicer J. 2004. Resources to combat math anxiety. Eisenhower National Clearinghouse Focus. 12(12): 1.

Stoehr K J. 2017. Mathematics Anxiety: One Size Does Not Fit All. Journal of Teacher Education. 68(1): 69-84. Available at: doi: 10.1177/0022487116676316 (Accessed: February 2020). 
Sun K. 2014. Math can-do. USA Today 09/07/2014 Available at: https://eu.usatoday.com/ story/opinion/2014/07/09/math-misconceptions-education-reform-column/12430181/ (Accessed: February 2020).

Turner J C, Midgley C, Meyer D K, Gheen M, Anderman E M, Kang Y, Patrick H. 2002. The classroom environment and students' reports of avoidance strategies in mathematics: A multimethod study. Journal of Educational Psychology. 94: 88-106.

Trujillo K M, Hadfield O D. 1999. Tracing the roots of mathematics anxiety through in-depth interviews with preservice elementary teachers. College Student Journal, 33(2): 219.

Vukovic R K, Kieffer M J, Bailey S P, Harari R R. 2013. Mathematics anxiety in young children: Concurrent and longitudinal associations with mathematical performance. Contemporary Educational Psychology. 38(1): 1-10.

Vygotsky LS. 1978. Mind in Society: the development of higher psychological processes. Cambridge MA: Harvard University Press.

Wright K. 2009. Do calculation errors by nurses cause medication errors in clinical practice? A literature review. Nurse Education Today. 30: 85-97. Available at: https://www.ncbi.nlm.nih.gov/pubmed/19666199 (Accessed: February 2020). 


\section{Appendix A:}

\section{Instructions:}

Please give each sentence a score to reflect how you would feel in the situation described. Circle the number which best describes your response.

\begin{tabular}{|c|c|c|c|c|c|}
\hline & Fine & $\begin{array}{l}\text { Somewhat } \\
\text { anxious }\end{array}$ & $\begin{array}{l}\text { Moderately } \\
\text { anxious }\end{array}$ & $\begin{array}{l}\text { Rather } \\
\text { anxious }\end{array}$ & $\begin{array}{l}\text { Highly } \\
\text { anxious }\end{array}$ \\
\hline $\begin{array}{l}\text { 1. Having to use the } \\
\text { mathematics tables } \\
\text { in the BNF }\end{array}$ & 1 & 2 & 3 & 4 & 5 \\
\hline $\begin{array}{l}\text { 2. Thinking about a } \\
\text { mathematics test the } \\
\text { day before the test } \\
\text { occurs }\end{array}$ & 1 & 2 & 3 & 4 & 5 \\
\hline $\begin{array}{l}\text { 3. Watching the tutor } \\
\text { doing mathematics } \\
\text { on the whiteboard }\end{array}$ & 1 & 2 & 3 & 4 & 5 \\
\hline $\begin{array}{l}\text { 4. Taking a } \\
\text { mathematics exam }\end{array}$ & 1 & 2 & 3 & 4 & 5 \\
\hline $\begin{array}{l}\text { 5. Being given an } \\
\text { assignment on } \\
\text { mathematics, to be } \\
\text { submitted in the next } \\
\text { lecture }\end{array}$ & 1 & 2 & 3 & 4 & 5 \\
\hline $\begin{array}{l}\text { 6. Listening to a lecture } \\
\text { on mathematics }\end{array}$ & 1 & 2 & 3 & 4 & 5 \\
\hline $\begin{array}{l}\text { 7. Listening to another } \\
\text { student explain a } \\
\text { mathematics formula }\end{array}$ & 1 & 2 & 3 & 4 & 5 \\
\hline $\begin{array}{l}\text { 8. Being given a surprise } \\
\text { test on mathematics } \\
\text { in a lecture }\end{array}$ & 1 & 2 & 3 & 4 & 5 \\
\hline
\end{tabular}


9. Starting a new topic in mathematics

\section{Instructions:}

Please give each sentence a score to reflect how you would feel in the situation described. Circle the number which best describes your response.

\begin{tabular}{|c|c|c|c|c|c|}
\hline & Fine & $\begin{array}{l}\text { Somewhat } \\
\text { anxious }\end{array}$ & $\begin{array}{l}\text { Moderatel } \\
\text { y anxious }\end{array}$ & $\begin{array}{l}\text { Rather } \\
\text { anxious }\end{array}$ & $\begin{array}{l}\text { Highly } \\
\text { anxious }\end{array}$ \\
\hline $\begin{array}{l}\text { 1. Having to use the drug } \\
\text { calculations tables in } \\
\text { the BNF }\end{array}$ & 1 & 2 & 3 & 4 & 5 \\
\hline $\begin{array}{l}\text { 2. Thinking about a drug } \\
\text { calculations test the day } \\
\text { before the test occurs }\end{array}$ & 1 & 2 & 3 & 4 & 5 \\
\hline $\begin{array}{l}\text { 3. Watching the tutor } \\
\text { doing drug calculations } \\
\text { on the whiteboard }\end{array}$ & 1 & 2 & 3 & 4 & 5 \\
\hline $\begin{array}{l}\text { 4. Taking a drug } \\
\text { calculations exam }\end{array}$ & 1 & 2 & 3 & 4 & 5 \\
\hline $\begin{array}{l}\text { 5. Being given an } \\
\text { assignment on drug } \\
\text { calculations, to be } \\
\text { submitted in the next } \\
\text { lecture }\end{array}$ & 1 & 2 & 3 & 4 & 5 \\
\hline $\begin{array}{l}\text { 6. Listening to a lecture on } \\
\text { drug calculations }\end{array}$ & 1 & 2 & 3 & 4 & 5 \\
\hline $\begin{array}{l}\text { 7. Listening to another } \\
\text { student explain a drug } \\
\text { calculation formula }\end{array}$ & 1 & 2 & 3 & 4 & 5 \\
\hline
\end{tabular}


8. Being given a surprise test on drug calculations in a lecture

1

2

3

4

5

9. Starting a new topic in drug calculations 